РУДАКОВА Екатерина Константиновна - кандидат политических наук, доцент кафедры международных отношений и политологии, старший научный сотрудник Нижегородского государственного лингвистического университета им. Н.А. Добролюбова (603155, Россия, г. Нижний Новгород, ул. Минина, 31a; ekaterina-rudakowa@mail.ru)

\title{
МНОГОФАКТОРНЫЙ АНАЛИЗ ВНУТРЕННИХ ДЕМОГРАФИЧЕСКИХ УГРОЗ РОССИИ
}

\begin{abstract}
Аннотация. Статья посвящена состоянию демографической безопасности России. На основе анализа статистических показателей Росстата об уровнях рождаемости, смертности, абортов, урбанизации, заболеваемости, продолжительности жизни населения делается вывод, что в России сохраняется суженый тип воспроизводства населения, при котором смертность значительно превышает рождаемость. Фактор миграции рассматривается государством как единственный механизм восполнения численности населения в свете прогнозируемого дальнейшего спада численности населения. При этом в стратегии не говорится о возможности повышения рождаемости за счет профилактики абортов и необходимости поддержки позитивных форм репродуктивного поведения молодежи. В статье автор приводит срез результатов анализа данных об убыли и приросте населения по регионам России и делает вывод о продолжающемся процессе урбанизации и опасности для общественной и государственной безопасности формирования крупных городских агломераций, ярким доказательством чего стала эпидемия COVID-19. Ключевые слова: депопуляция, демография, демографический переход, технологическая революция, рождаемость, миграция, репродукция, аборты, безопасность
\end{abstract}

$\mathrm{B}_{\mathrm{C}}^{\mathrm{P}}$ России демографический кризис носит затяжной системный характер. С 2017 г. после небольшого подъема рождаемости предыдущих лет вновь фиксируется естественная убыль населения, которая так же, как и в большинстве стран Европы, компенсируется за счет миграционных потоков. Как и в Европе, руководство России смотрит на миграцию как на панацею в решении демографических задач. По прогнозам ООН, при сохранении текущих тенденций депопуляции к 2050 г. население России сократится до 100-120 млн чел., а население Европы - до 520 млн чел. При этом этноконфессиональная карта Евразии претерпит существенные изменения за счет роста миграции и сокращения воспроизводства коренного населения, что вызовет комплекс социально-экономических последствий.

По официальным данным статистики, численность населения России (с учетом Республики Крым) на 1 октября 2019 г. составила 146,7 млн чел. Несмотря на то что до 2019 г. наблюдался незначительный подъем общей численности населения, основными показателями для понимания тенденции демографического спада являются показатели естественного прироста и миграционного сальдо ${ }^{1}$. Данные свидетельствуют, что в России прирост численности населения осуществляется исключительно за счет мигрантов, который компенсирует естественную убыль населения (см. табл. 1).

На протяжении последних 15 лет убыль населения в России составляет ежегодно в среднем около 2 млн чел., что значительно превышает американские, европейские и общемировые показатели (смертность в России в 2 раза больше европейской и в 1,5 раза больше, чем в США), при этом рождаемость в России составляет в среднем около 1,3 млн чел. в год. Согласно данным Росстата за

1 Рождаемость, смертность и естественный прирост населения по субъектам РФ за 2019 г. - Федеральная служба государственной статистики. Доступ: https://rosstat.gov.ru/ folder/12781 (проверено 16.11.2020). 
Таблица 1

Данные об общей численности населения России (млн чел.), естественном и миграционном приросте (в тыс. чел.) 2018-2020 гг."

\begin{tabular}{|l|c|c|c|c|c|c|}
\hline \multicolumn{1}{|c|}{ Показатели/Год } & $\mathbf{2 0 0 0}$ & $\mathbf{2 0 1 0}$ & $\mathbf{2 0 1 5}$ & $\mathbf{2 0 1 6}$ & $\mathbf{2 0 1 8}$ & $\mathbf{2 0 1 9}$ \\
\hline $\begin{array}{l}\text { Численность населения, } \\
\text { млн чел. }\end{array}$ & 146,3 & 142,9 & 146,5 & 146,8 & 146,9 & 146,7 \\
\hline $\begin{array}{l}\text { Естественный прирост, } \\
\text { тыс. чел. }\end{array}$ & $-958,5$ & $-239,6$ & 32,1 & $-2,3$ & $-135,8$ & $-168,4$ \\
\hline $\begin{array}{l}\text { Миграционный прирост, } \\
\text { тыс. чел. }\end{array}$ & 362,63 & 271,5 & 245,4 & 262,0 & 211,9 & - \\
\hline
\end{tabular}

* Российский статистический ежегодник - 2018. М.: Росстат. 2018. С. 76-84.

2020 г., смертность населения в России составила 1,72 млн., рождаемость 1,26 млн чел. ${ }^{1}$

Для понимания ситуации в целом очень важна региональная картина. Для большинства субъектов РФ характерна общая убыль населения и высокий процент внутренней миграции, за исключением некоторых субъектов федерации.

Общей тенденцией для всех регионов России является сокращение численности коренного населения и его старение, ежегодно фиксируется стабильный спад рождаемости. В 2018 г. доля сельского населения в приросте рождаемости составила всего 399,1 тыс. чел. С учетом того, что в России, по данным переписи 2010 г., 153,1 тыс. сельских населенных пунктов, данная картина свидетельствует о вымирании села; уже около $12,6 \%$ сел в России не имеют постоянного населения. Пик рождаемости после 1990-х гг. (406,7 тыс. чел.) на селе был зафиксирован в 2014 г. (547,8 тыс. чел.), затем неуклонно наблюдался спад рождаемости ${ }^{2}$. Этому способствует и урбанизация: более $2 / 3$ населения России живет в городах (рост урбанизации после очередного падения в 1990-х начался с 2014 г. и достиг к 2019 г. отметки в 109,5 млн (см. табл. 2).

В регионах России, за редким исключением, население не превышает 3 млн чел., в Дальневосточном и Сибирском федеральном округах таких регионов и вовсе нет. В ходе изучения данных Росстата по показателю рождаемости (в период с 2008 по 2018 г.) было определено, что спад рождаемости фиксируется во всех регионах России (см. табл. 3). Наиболее низкая плотность населения в северных и восточных регионах страны - менее 0,1-0,9 по показателю плотности ${ }^{3}$. За последнее десятилетие на $15 \%$ сократилась численность населения в Республике Коми, Камчатском крае, Архангельской, Магаданской, Мурманской и Сахалинской обл. На 10-15\% сократилась численность населения в республиках Карелия, Мордовия и Саха (Якутия), Приморском и Хабаровском краях, Амурской, Владимирской, Ивановской, Кировской, Костромской, Курганской, Курской, Новгородской, Псковской, Рязанской, Смоленской, Тамбовской, Тверской, Тульской и Читинской обл.

1 Рождаемость, смертность и естественный прирост населения по субъектам РФ за 2019 г. - Федеральная служба государственной статистики. Доступ: https://rosstat.gov.ru/ folder/12781 (проверено 16.11.2020).

2 Российский статистический ежегодник - 2018. М.: Росстат. 2018. С. 76-84.

3 Плотность населения Российской Федерации на 1 января 2019 г. - Федеральная служба государственной статистики. Доступ: http://www.gis.gks.ru/StatGis2015/d/9/9ba51baf-8118509a-a0a8-c9fbcb4f477c.png (проверено 16.11.2020). 
Таблица 2

Прирост/убыль в федеральных округах, 2018 гг.

\begin{tabular}{|l|c|c|c|}
\hline \multicolumn{1}{|c|}{ Федеральные округа } & Убыль, \% & Убыль, чел. & $\begin{array}{c}\text { Общая численность населения, } \\
\text { чел. }\end{array}$ \\
\hline Северо-Кавказский & $+0,43$ & 43267 & 9845114 \\
\hline Центральный & $+0,16$ & 66646 & 39344736 \\
\hline Северо-Западный & $+0,14$ & 20067 & 13962037 \\
\hline Южный & $+0,07$ & 12697 & 16448201 \\
\hline Приволжский & $-0,49$ & -145483 & 29469954 \\
\hline Дальневосточный & $-0,41$ & -33978 & 8205612 \\
\hline Сибирский & $-0,33$ & -56822 & 17201745 \\
\hline Уральский & $-0,04$ & -6107 & 12353176 \\
\hline
\end{tabular}

* Общий прирост постоянного населения. - Федеральная служба государственной статистики. Разд. «Демография. Численность и состав населения». Доступ: https://rosstat.gov.ru/ folder/12781 (проверено 16.11.2020).

Таблица 3

Субъекты РФ с населением свыше 3 млн чел.

\begin{tabular}{|l|c|c|c|}
\hline \multirow{2}{*}{\multicolumn{1}{|c|}{ Субъект РФ }} & \multicolumn{3}{|c|}{ Численность населения, чел. } \\
\cline { 2 - 4 } & $\mathbf{2 0 1 6}$ & $\mathbf{2 0 1 7}$ & $\mathbf{2 0 1 8}$ \\
\hline Город Москва & 12443566 & 12560873 & 12646679 \\
\hline Московская область & 7463427 & 7551516 & 7645255 \\
\hline Город Санкт-Петербург & 5316757 & 5367912 & 5390977 \\
\hline Краснодарский край & 5587182 & 5625827 & 5661848 \\
\hline Свердловская область & 4327299 & 4320477 & 4313190 \\
\hline Ростовская область & 4225903 & 4211386 & 4200071 \\
\hline Республика Башкортостан & 4065132 & 4057148 & 4044578 \\
\hline Республика Татарстан & 3889768 & 3896456 & 3900758 \\
\hline Тюменская область & 3676215 & 3708185 & 3740252 \\
\hline Челябинская область & 3497679 & 3484395 & 3471061 \\
\hline Нижегородская область & 3241232 & 3224687 & 3208785 \\
\hline Самарская область & 3198596 & 3188276 & 3181285 \\
\hline
\end{tabular}

Резко выросла убыль населения в федеральных округах Дальнего Востока, Приволжья, Сибири и Урала. Резко выросла (в 1,5-2 раза) убыль населения в Астраханской, Нижегородской, Свердловской, Смоленской, Тамбовской, Тульской, Кемеровской, Воронежской обл., республиках Башкортостан и Мордовия.

В 2019 г. в Москве, Московской обл., Санкт Петербурге и Ленинградской обл. 
Субъекты федерации с убылью населения более $1 \%$ в год, 2018 г.

\begin{tabular}{|l|c|c|c|}
\hline \multicolumn{1}{|c|}{ Субъект федерации } & Убыль, & Убыль, чел. & $\begin{array}{c}\text { Общая численность } \\
\text { населения, чел. }\end{array}$ \\
\hline Амурская область & $-3,92$ & -5230 & 795809 \\
\hline Магаданская область & $-2,00$ & -2857 & 142663 \\
\hline Тамбовская обл. & $-1,71$ & -17586 & 1024759 \\
\hline Еврейская АО & $-1,30$ & -2101 & 160964 \\
\hline Курганская область & $-1,28$ & -10836 & 840118 \\
\hline Республика Коми & $-1,27$ & -10638 & 835553 \\
\hline Республика Мордовия & $-1,19$ & -9552 & 800280 \\
\hline Тверская область & $-1,11$ & -14237 & 1276754 \\
\hline Псковская область & $-1,08$ & -6895 & 633098 \\
\hline Ивановская область & $-1,03$ & -10466 & 1009413 \\
\hline Пензенская обл. & $-1,02$ & -13552 & 1324878 \\
\hline Новгородская обл. & $-1,02$ & -6180 & 603386 \\
\hline Орловская область & $-1,04$ & -7780 & 743356 \\
\hline Республика Калмыкия & $-1,00$ & -2766 & 274029 \\
\hline
\end{tabular}

* Общий прирост постоянного населения. - Федеральная служба государственной статистики. Разд. «Демография. Численность и состав населения». Доступ: https://rosstat.gov.ru/ folder/12781 (проверено 16.11.2020).

в совокупности проживали 27,5 млн чел. ${ }^{1}$ Наибольший прирост наблюдался в Ленинградской обл. $(1,85 \%)$, городах федерального значения Севастополе $(1,48 \%)$ и Москве $(0,87 \%)$, Московской обл. $(1,28 \%)$ и Республике Чечня $(1,38 \%)$. Эти регионы являются крупнейшими экономическими/инвестиционными центрами федеральных округов и, как следствие неравномерного экономического развития, фактически оттягивают население из менее развитых регионов. За счет этого происходит создание крупных городских агломераций с комплексом экологических и социальных проблем. Концентрация подавляющего большинства населения всего в нескольких крупных городах является серьезным риском для государственной безопасности страны в случае воздушной точечной атаки или массового применения биологического и химического оружия; существует опасность мгновенного подавления противника за счет массовых человеческих жертв (см. табл. 5). Пандемия COVID-19 в 2020 г. показала, насколько опасными могут стать крупные города с точки зрения общественной безопасности.

По-прежнему сохраняются высокие показатели эмиграции из России. По итогам в 2017 г. Россию покинули 4,56 млн чел., а в 2018 г. - 4,78 млн чел. Большинство из них - молодые люди с высшим образованием и специализа-

1 Численность постоянного населения в среднем за год. - Федеральная служба государственной статистики. Доступ: https://rosstat.gov.ru/folder/12781?print=1 (проверено 16.11.2020). 
Таблииа 5

Регионы с общим приростом населения в субъектах РФ, 2018 г.

\begin{tabular}{|l|c|c|c|}
\hline \multicolumn{1}{|c|}{ Субъект федерации } & Прирост, \% & $\begin{array}{c}\text { Прирост, } \\
\text { тыс. чел. }\end{array}$ & $\begin{array}{c}\text { Общая численность } \\
\text { населения, чел. }\end{array}$ \\
\hline Ленинградская область & $+1,85$ & 34051 & 1830841 \\
\hline Севастополь & $+1,48$ & 6542 & 439941 \\
\hline Республика Чечня & $+1,38$ & 19970 & 1446966 \\
\hline Московская область & $+1,28$ & 96262 & 7515516 \\
\hline Москва & $+0,87$ & 108811 & 12560873 \\
\hline Тюменская область & $+0,85$ & 31568 & 3708185 \\
\hline Республика Тыва & $+0,83$ & 2701 & 323073 \\
\hline Краснодарский край & $+0,79$ & 44815 & 5625827 \\
\hline Республика Дагестан & $+0,72$ & 22241 & 3075006 \\
\hline Калининградская область & $+0,70$ & 7588 & 998392 \\
\hline Санкт-Петербург & $+0,59$ & 31954 & 5367912 \\
\hline Ямало-Ненецкий АО & $+0,54$ & 2932 & 540013 \\
\hline Ханты-Мансийский АО - Югра & $+0,52$ & 8721 & 1659435 \\
\hline Республика Алтай & $+0,36$ & 803 & 218464 \\
\hline Республика Адыгея (Адыгея) & $+0,30$ & 1368 & 454060 \\
\hline Новосибирская область & $+0,23$ & 4534 & 1952137 \\
\hline Республика Татарстан (Татарстан) & $+0,11$ & 4344 & 3896456 \\
\hline Республика Кабардино-Балкария & $+0,04$ & 391 & 866023 \\
\hline
\end{tabular}

* Общий прирост постоянного населения. - Федеральная служба государственной статистики. Разд. «Демография. Численность и состав населения». Доступ: https://rosstat.gov.ru/ folder/12781 (проверено 16.11.2020).

цией (актуален вопрос о целесообразности затрат на бюджетное образование тех, кто затем выезжает для работы за границу) ${ }^{1}$.

Причины убыли населения напрямую связаны с демографическими установками молодого поколения России. Только $33 \%$ семей с одним ребенком хотят иметь еще детей; семьи с двумя детьми только в 7\% случаев задумываются о рождении большего числа детей. Только 7\% российских семей воспитывают троих детей и более, $28 \%$ - двоих, 65\% - одного. Значительно сужается репродуктивное окно. Все чаще появление первого ребенка происходит, когда женщина достигает зрелого возраста. Все чаще молодые люди выбирают образ жизни, который не предполагает создания семьи и рождения детей. В этом первостепенную роль играют массмедиа, которые транслируют потребительскую модель поведения и формируют сниженные репродуктивные установки.

1 Сведения о выбывших гражданах РФ. - Федеральная служба государственной статистики. Доступ: https://rosstat.gov.ru/monitoring?document=50669 (проверено 16.11.2020). 
О кризисе семьи свидетельствуют и данные по разводам (в 2015 г. на 116068 зарегистрированных браков пришлось 611646 разводов) ${ }^{1}$.

В России сохраняются высокие показатели смертности трудоспособного населения; это, в свою очередь, влияет на показатели продолжительности жизни. Мужчины трудоспособного возраста составляют почти $1 / 3$ числа умерших; основные причины - сердечно-сосудистые заболевания (55\%), болезни кроветворения, новообразования, болезни органов пищеварения, дыхания. Процент смертности от сердечно-сосудистых заболеваний выше в разы, чем в странах Европы. Нельзя сбрасывать со счетов и причины, связанные с отравлениями, самоубийствами, транспортными происшествиями и несчастными случаями. Медленно, но снижается младенческая смертность, которая в среднем за последние 5 лет составляет 5853 чел. в год, но это все равно в 2 раза выше, чем в развитых странах Европы, Канады и США. Злокачественные образования являются второй причиной смертности и инвалидизации в России после сердечно-сосудистых заболеваний. Специалисты полагают, что следует ожидать роста распространенности сердечно-сосудистых заболеваний в связи с ожидаемым увеличением продолжительности жизни и старением населения. Исследование проблематики показало, что в период с 1999 г. наблюдается отчетливая динамика роста распространенности онкологических заболеваний в России (см. табл. 6) [Турсун-Заде 2018].

Таблица 6

Динамика распространенности онкологических заболеваний, 1999-2016 гг.

\begin{tabular}{|l|c|l|c|}
\hline $\begin{array}{l}\text { Все новообразования } \\
\text { у женщин }\end{array}$ & $>$ в 1,6 раза & $\begin{array}{l}\text { Онкология } \\
\text { предстательной железы }\end{array}$ & $\begin{array}{c}\text { > в } 5,2 \text { раза } 1,2 \text { раза } \\
\text { у женщин }\end{array}$ \\
\hline $\begin{array}{l}\text { Все новообразования } \\
\text { у мужчин }\end{array}$ & $>$ в 1,8 раза & $\begin{array}{l}\text { Онкология } \\
\text { желудка }\end{array}$ & $\begin{array}{l}\text { в } 2,5 \text { раза у мужчин, } \\
\text { в 2 раза у женщин }\end{array}$ \\
\hline $\begin{array}{l}\text { Онкология } \\
\text { молочной железы }\end{array}$ & $>$ в 2,1 раза & $\begin{array}{l}\text { Колоректальная } \\
\text { онкология }\end{array}$ & \multicolumn{2}{|l}{} \\
\hline
\end{tabular}

Курение по-прежнему остается причиной многих заболеваний и высокой смертности в России. За последние годы в России наблюдается настоящая эпидемия женского курения (по данным 2017 г., в России курили 43\% мужчин и $14 \%$ женщин). В 2017 г. курение стало причиной смерти 211,5 тыс. чел. мужского населения и 23,4 тыс. чел. женского [Кузнецова 2019]. По данным исследований, меньше всего курят в республиках Татарстан, Чечня и Ингушетия. За последний год выросла заболеваемость гепатитом $C$ (в 2019 г. - 93,3 тыс. чел., в 2020 г. - 117,9 тыс. чел.); туберкулезом (в 2018 г. - 65,2 тыс. чел., в 2019 г. 90,4 тыс. чел., в 2020 г. - 97,6 тыс. чел.); ВИЧ (в 2018 г. - 85,9 тыс. чел., в 2019 г. $-86,8$ тыс. чел., в 2020 г. - 91,0 тыс. чел., в т.ч. детей -61 чел.) ${ }^{2}$. От наркомании в России ежегодно умирают более 100 тыс. чел. Самый низкий процент наркомании наблюдается в мусульманских республиках России, где сохраняется крайне негативное отношение к наркомании и табакокурению. Не снижается

1 Браки: раздел «Демография». - Федеральная служба государственной статистики. Доступ: https://rosstat.gov.ru/folder/12781; Разводы: раздел «Демография». - Федеральная служба государственной статистики. Доступ: https://rosstat.gov.ru/folder/12781

2 Заболеваемость населения отдельными инфекционными заболеваниями (по данным Роспотребнадзора) (на январь 2020 г.). - Федеральная служба государственной статистики. Доступ: http://rostov.old.gks.ru/wps/wcm/connect/rosstat_ts/rostov/resources/069032804c1075 alb6a4f7b4bce00d93/Заболеваемость+населения+отдельными+инфекционными+болезня ми.htm (проверено 16.11.2020). 
распространенность алкоголизма, табакокурения. Лидерами по алкоголизации являются Чукотка, Якутия и Ненецкий автономный округ; самая большая смертность от алкоголизма наблюдается на Дальнем Востоке (см. табл. 7).

Таблица 7

Данные Росстата о рождаемости и смертности, причинах смертности в России, 2019-2020 гг., тыс. чел.

\begin{tabular}{|l|c|c|}
\hline \multicolumn{1}{|c|}{ Значение } & $\mathbf{2 0 1 9}$ & $\mathbf{2 0 2 0}$ \\
\hline Естественный прирост (+), убыль (-) & $-46,5$ & $-45,3$ \\
\hline Родившихся & 126,0 & 118,8 \\
\hline Умерших & 172,5 & 164,1 \\
\hline из них детей (в возрасте до 1 года) & 0,6 & 0,5 \\
\hline из них: от болезней системы кровообращения & 85,1 & 77,1 \\
\hline новообразований & 26,6 & 24,7 \\
\hline внешних причин смерти & 12,9 & 11,6 \\
\hline болезней органов пищеварения & 9,2 & 9,3 \\
\hline болезней органов дыхания & 5,9 & 5,4 \\
\hline инфекционных и паразитарных болезней & 3,0 & 2,6 \\
\hline транспортных несчастных случаев & 1,5 & 1,5 \\
\hline самоубийств & 1,3 & 1,3 \\
\hline убийств & 0,8 & 0,7 \\
\hline случайных отравлений алкоголем & 1,0 & 0,6 \\
\hline
\end{tabular}

По мнению экспертов, старение населения станет одним из наиболее сложных демографических вызовов для государств в XXI в. Россия - не исключение: коэффициент демографической нагрузки в 2019 г., когда была начата пенсионная реформа и повышен порог выхода на пенсию, составила 208 чел. старше 65 лет на 1000 жителей трудоспособного возраста (49-е место в мире). Для сопоставления: в Белоруссии значение этого показателя составляет 216 чел., на Украине - 224 чел., в Казахстане - 104 чел. Для стран Средней Азии, в которых наблюдается пик рождаемости, эта проблема станет актуальной лишь к 2040 г. Самые высокие темпы старения населения по причине снижения рождаемости наблюдаются в России в республиках Дагестан, Якутия, Алтай, Тыва, в Ненецком, Ханты-Мансийском, Ямало-Ненецком, Чукотском автономных округах, в Архангельской и Магаданской областях. Регионы с постоянным притоком населения, такие как Московская обл., Санкт-Петербург, Севастополь, демонстрируют низкие показатели старения за счет мигрантов. Другим показателем является коэффициент пенсионной нагрузки: он наиболее высок в центральных регионах, ставших донорами внутренних мигрантов для Московской, Ленинградской, Екатеринбургской обл. В России высока доля работающих пенсионеров в крупных городах (Москва, Санкт-Петербург); в сельских регионах она значительно ниже. По прогнозам, пенсионная реформа 2019 г. будет иметь временный эффект снижения пенсионной нагрузки в течение 17 лет, после чего опять потребуется повысить пенсионный возраст. В 2028 г. в большинстве регионов прогнозируется увеличение пенсионной нагрузки [Петросян и др. 2019].

Снижение рождаемости - это прямое следствие абортов. Россия занимает 
одно из первых мест в мире после Китая и США по числу абортов в год. При этом в демографической концепции нет ни слова о необходимости сокращения числа абортов для повышения уровня рождаемости в пределах 1-2 млн чел. в год ${ }^{1}$. Только по данным официальной статистики, в 2018 г. было сделано 587,1 тыс. абортов, хотя официальная статистика скорее всего не отражает реального положения дел с незаконными медикаментозными абортами. Около 43,5 тыс. абортов составляют аборты у беременных первым ребенком $(7,7 \%) ; 4,64$ тыс. абортов было сделано молодыми девушками в возрасте до 17 лет. Только согласно данным официальной статистики, за период с 1990 по 2019 г. было сделано 55,35 млн абортов ${ }^{2}$. Специалисты относят к абортивным средствам внутриматочные спирали. В России в 2018 г. на 1000 женщин приходилось около 99,6 тех, кто устанавливает спираль ${ }^{3}$.

Что касается демографических сценариев, российские демографы представили низкий, средний и высокий вариант прогноза численности населения России до 2036 г. (см. табл. 8). В соответствии с низким прогнозом население России сократится к 2035 г. на 8 млн чел. по сравнению с уровнем 2020 г. и составит 139,7 млн чел., что будет связано со снижением миграции. Средний и высокий вариант прогнозируют увеличение численности населения до 148 млн чел. при условии сохранения высокого уровня миграции в пределах 350-400 тыс. чел. в год.

Таблица 8

Изменение численности населения и миграционного прироста по вариантам прогноза ${ }^{*}$, тыс. чел.

\begin{tabular}{|l|l|l|l|}
\hline Годы & \multicolumn{1}{|c|}{$\begin{array}{c}\text { Низкий } \\
\text { вариант прогноза }\end{array}$} & \multicolumn{1}{c|}{$\begin{array}{c}\text { Средний } \\
\text { вариант прогноза }\end{array}$} & \multicolumn{1}{c|}{$\begin{array}{c}\text { Высокий } \\
\text { вариант прогноза }\end{array}$} \\
\hline \multirow{4}{*}{2025} & Население: & Население: & Население: \\
& 144 032,2 & 145858,3 & 147582,4 \\
& Миграционный прирост: & Миграционный прирост: & Миграционный прирост: \\
& 35,3 & 253,4 & 361,8 \\
\hline \multirow{4}{*}{2030} & Население: & Население: & Население: \\
& 139787,5 & 144274,0 & 148361,0 \\
& Миграционный прирост: & Миграционный прирост: & Миграционный прирост: \\
& 22,6 & 258,5 & 376,8 \\
\hline \multirow{4}{*}{2035} & Население: & Население: & Население: \\
& 135201,7 & 142993,3 & 149760,8 \\
& Миграционный прирост: & Миграционный прирост: & Миграционный прирост: \\
& 15,7 & 236,6 & 386,8 \\
\hline
\end{tabular}

* Изменение численности населения по вариантам прогноза. - Федеральная служба государственной статистики. Разд. «Демография. Численность и состав населения». Доступ: https://rosstat.gov.ru/folder/12781 (проверено 16.11.2020).

Таким образом, необходимо признать, что по большинству показателей

1 Указ Президента РФ «Об утверждении Концепции демографической политики Российской Федерации на период до 2025 года» от 09.10.2007 N 1351 (ред. от 01.07.2014). Доступ: http://www.consultant.ru/documemt/cons_doc_LAW_71673 (проверено 30.11.2020).

2 Число абортов по данным Росстата в 1990-2019 годах. - Федеральная служба государственной статистики. Доступ: https://rosstat.gov.ru/free_doc/new_site/population/ zdrav/zdra36_bd.htm

3 Александрова Г.А., Голубев Н.А., Тюрина Е.М., Огрызко Е.В., Шелепова Е.А., Залевская О.В. 2019. Основные показатели здоровья матери и ребенка, деятельность службы охраны детства и родовспоможения в Российской Федерации. - Статистические материалы Министерства здравоохранения РФ. М. С. 123-126. 
демографическая безопасность в России находится в системном затянувшемся кризисе, что в будущем неизменно скажется на темпах экономического роста, бюджетном обеспечении, обороне страны, а изменения в возрастной структуре населения потребуют больших дотаций на медицину и социальную помощь. При этом важно отметить, что даже при самом оптимистичном сценарии (высокий вариант прогноза) демографы прогнозируют сохранение тенденций естественной убыли населения. Видится, что государство упускает очень много механизмов повышения рождаемости (профилактика абортов, работа с молодежью по формированию позитивных форм репродуктивного поведения, формирование культуры жизни с целью борьбы с пагубными привычками курения, наркомании, алкоголизма; противодействие организациям, распространяющим деструктивные и радикальные идеи, подрывающие основы семьи и уклада жизни народов России). Низкий уровень рождаемости, даже если он будет компенсирован за счет миграции, неизменно приведет к старению коренного населения, его замещению мигрантами, когда воспроизводство населения по варианту прироста уже будет невозможно ${ }^{1}$.

\title{
Список литературы
}

Кузнецова П. 2019. Курение как фактор сокращения ожидаемой продолжительности жизни в России. - Демографическое обозрение. Т. 6. № 3. С. 31-57.

Петросян А., Шевчук Е., Кириллов П., Мозгунов Н. 2019. Географические особенности старения населения России. - Демографическое обозрение. Т. 6. № 2. С. 55-83.

Турсун-Заде Р. 2018. Оценка распространенности злокачественных новообразований в России с применением модели заболеваемость-смертность. Демографическое обозрение. Т. 5. № 3. С. 103-126.

RUDAKOVA Ekaterina Konstantinovna, Cand.Sci. (Pol.Sci.), Associate Professor of the Chair of International Relations and Political Science; Senior Researcher at the Dobroljubov State Linguistics University of Nizhny Novgorod (31a Minina St, Nizhny Novgorod, Russia,603155; ekaterina-rudakowa@mail.ru)

\section{MULTI-FACTOR ANALYSIS OF INTERNAL DEMOGRAPHIC THREATS FOR RUSSIA}

\begin{abstract}
The article is devoted to the problem of demographic security in Russia. Based on the analysis of Rosstat statistics on fertility, mortality, abortion, urbanization, morbidity, and life expectancy, the paper shows a narrowed type of population reproduction in Russia, at which mortality is significantly higher than the birth rate. Moreover, the state considers the migration factor as the only mechanism of population replenishment in the light of the projected further decline in the population. Its strategy does not say anything about the possibility of increasing the birth rate through the prevention of abortion and the need to support positive forms of reproductive behavior of young people. The article also provides a snapshot of the analysis of data on population loss and growth by regions of Russia, concludes the ongoing process of urbanization and the danger to public and state security of a large urban agglomerations, a striking proof of which was the COVID-19 pandemic.
\end{abstract}

Keywords: depopulation, demography, demographic transition, technological revolution, birth rate, migration, reproduction, abortion, safety

1 Изменение численности населения по вариантам прогноза. - Федеральная служба государственной статистики. Разд. «Демография. Численность и состав населения». Доступ: https://rosstat.gov.ru/folder/12781 (проверено 16.11.2020). 